\title{
Alliance for Health Policy and Systems Research: aims, achievements and ambitions
}

\author{
Abdul Ghaffara,b, Nhan Trana, Etienne Langloisa, Zubin Shroffa and \\ Dena Javadia
}

a Alliance for Health Policy and Systems Research, World Health Organization, Geneva, Switzerland

b Corresponding author: ghaffara@who.int

\section{Article history}

Publication date: February 2017

Ghaffar A, Tran N, Langlois E,

Shroff Z, Javadi D. Alliance for Health Policy and Systems Research: aims, achievements and ambitions. Public Health Res Pract. 2017;27(1):e2711703. doi: http://dx.doi. org/10.17061/phrp2711703

\section{Key points}

- The Alliance for Health Policy and Systems Research, hosted by the World Health Organization, aims to promote research to support health policies and improve the performance of health systems in low- and middle-income countries

- Since 1999, the Alliance has helped to build the field of health policy and systems research through advocacy, innovation, convening and thoughtleading activities - for instance, promoting demand-driven research led by decision makers

- The Alliance will continue to engage with policy makers, researchers and other stakeholders to increase the impact of research on strengthening health systems worldwide

\section{Abstract}

The Alliance for Health Policy and Systems Research was established in 1999 and is hosted as an international partnership by the World Health Organization (WHO). The Alliance emerged from recommendations of the 1996 WHO Ad Hoc Committee on Health Research, which recognised the role of research in strengthening health policies and the overall development of health systems.

Work towards the Alliance's mission - to promote the generation and use of health policy and systems research (HPSR) as a means to strengthen health systems in low- and middle-income countries - historically focused on three areas: generation of policy and systems knowledge, promotion of its use in decision making to improve the performance of health systems, and strengthening researchers' and decision makers' capacity to engage in these efforts. Now, after nearly 20 years of learning and accomplishments, the Alliance is launching new strategic objectives to reflect a changed context, and new challenges and opportunities.

Over the coming years, the Alliance plans to provide a unique forum for the HPSR community; support institutional capacity to conduct and use HPSR; stimulate the generation of knowledge and innovations to nurture learning and resilience in health systems; and increase demand for, and use of, knowledge for strengthening health systems.

\section{Aims}

The inadequacy of knowing merely what can work - as opposed to understanding how, why, when and for whom things work - has been brought home by uneven progress towards the achievement of the Millennium Development Goals and, more recently, by the Ebola epidemic. ${ }^{1}$ Even when there is knowledge about effective policies and interventions, these often cannot be implemented at scale or in equitable ways because of inefficient or fragmented systems. ${ }^{2}$ Decision makers often do not ask for research addressing real-world problems in health policy and systems. As well, leadership, and the capacity to generate and use knowledge to address weak health systems, are often lacking. ${ }^{3}$ Research addressing the determinants of 
health outside the health sector, or looking at how health and other Sustainable Development Goals are related, is neglected to some extent. What sort of knowledge is needed, how can it be generated, and how can its use be promoted to improve the performance of weak health systems? This challenge is the crux of the work of the Alliance for Health Policy and Systems Research (AHPSR).

The AHPSR was established in 1999 and is hosted as an international partnership by the World Health Organization (WHO). The Alliance's mandate emerged from the recommendations of the 1996 WHO Ad Hoc Committee on Health Research, which recognised the role of research in strengthening health policies and in the overall development of health systems. ${ }^{4,5}$ Work towards the Alliance's mission - to promote the generation and use of health policy and systems research (HPSR) as a means to strengthen health systems in low- and middle-income countries - historically focused on three areas: generation of policy and systems knowledge, promotion of its use in decision making to improve the performance of health systems, and strengthening the capacities of researchers and decision makers to engage in these efforts. ${ }^{6}$ Now, after nearly 20 years of learning and accomplishments, the Alliance is launching new strategic objectives to reflect a changed context, and new challenges and opportunities. ${ }^{1}$ During the coming years, the Alliance plans to:

- Provide a unique forum for the HPSR community

- Support institutional capacity to conduct and use HPSR

- Stimulate the generation of knowledge and innovations to nurture learning and resilience in health systems

- Increase the demand for, and use of, knowledge for strengthening health systems.

\section{Achievements}

Since 1999, the Alliance has emerged as a leader, playing an instrumental role in highlighting the importance of HPSR in the attainment of global health goals, as well as building momentum for the field. It has been an advocate for such research within WHO and towards decision making bodies, and has catalysed action that has resulted in significant developments. Alliance milestones include launching WHO's first strategy on HPSR, Changing mindsets; leading a platform for implementation research within $\mathrm{WHO}$; playing a key role in the establishment of a new society for health systems research, Health Systems Global; contributing significantly to three global symposiums on health systems research; and recognising the value of HPSR and health systems strengthening in the new report Health in 2015: from MDGs to SDGs. ${ }^{5,7}$

As a pioneering international collaboration focused on health systems research in low- and middleincome countries, the Alliance has much to be proud of. Its research grants have enabled more than 1100 researchers (the vast majority from low- and middleincome countries, and more than half of them women) to innovate, experiment and work with the Alliance to hone their skills, build institutional capacity and develop this nascent field. The quality of their work is evident from the nearly 300 peer-reviewed publications they have produced, which have been widely cited, and the Alliance's relevance is reflected in the more than 50 policies and practices directly influenced by these publications. Recognising that proactive engagement with policy communities is essential for evidenceinformed decision making, the Alliance has alerted more than 2000 policy makers at global, national, subnational and regional levels to the need for programs and policies to be informed by the best available evidence.

The role of the Alliance as a thought leader in HPSR is reflected in cross-cutting publications, such as the 2009 flagship report Systems thinking for health systems strengthening, which has been downloaded more than 4000 times in the past 2 years, as well as the 2014 report Medicines in health systems: advancing access, availability and appropriate use.8,9 The Alliance's 2012 HPSR methodology reader has been included in the syllabuses of masters programs in public health schools around the world. Publications such as the practical guide Implementation research in health and the 2014 methods reader Participatory action research have broken new ground by demonstrating the applicability of HPSR to a wide range of disciplines. ${ }^{10,11,12}$

The Alliance's research grants programs have enabled more than 300 projects in 70 countries and catalysed much innovation. This includes examining issues through a health systems lens - as demonstrated by the research on access to medicines and results-based financing - and introducing novel concepts, such as promoting research led by decision makers to ensure that it is demand driven. At the same time, the Alliance has strengthened capacities within countries to undertake HPSR. It has improved and broadened the quality of the debate, addressing a lack of knowledge by encouraging dialogue, sharing of ideas and learning. Through work in key thematic areas such as human resources for health, health financing, the role of nonstate providers, and access to medicines, the Alliance has been able to bring new knowledge to ignite discussion and further thinking.

Convening, collaborating and disseminating are key activities for increasing knowledge exchange and for amplifying different voices around issues to enable more effective responses. As a partnership hosted by WHO and with close ties to the HPSR community, the Alliance has brought together researchers and decision makers to bridge what are often viewed as two disparate worlds. The Alliance's most notable achievement is its leadership role in spearheading the inaugural Global Symposium on Health Systems Research in 2010; this led to the creation in 2012 of a new society, Health Systems Global, which is devoted to health systems research. 


\section{Ambitions}

Despite the progress made during the past 2 decades, there remains a serious need to generate more policy and systems knowledge to strengthen national health systems. As a thought leader, innovator, convener and advocate, the Alliance is in an ideal position, and has a critical responsibility, to contribute to this capacity-strengthening mission. The Alliance's future work is focused on the following areas:

- Teaching and training about HPSR in schools of public health and public policy. This work, involving both individual institutions and networks of institutions, will specifically target institutional (as opposed to individual) capacity strengthening. Approaches to this work include supporting the development and dissemination of teaching and training resources, tools, methods and frameworks, and developing a repository of knowledge products

- Improving the learning capacity of systems through models of embedded research, at both program and policy making levels, where national strategic and operational planning and policy dialogues take place. Analysis of national strategic policy dialogues and planning cycles would point to critical entry points where HPSR could improve these national processes. Here, there is an opportunity for cross-country learning

- Advocating for the field of HPSR through a comprehensive strategy that targets both decision makers and researchers. Effective advocacy will require surveying the field of HPSR, building momentum, engaging the community around new ideas and disseminating research results. The Alliance will continue to monitor and advocate for more resources for HPSR, and will aim to play a role in coordinating these efforts

- Convening stakeholders to bridge the communication gap between researchers and decision makers, and between disciplines in HPSR, as well as generating opportunities to share HPSR knowledge.

On its own, more and better knowledge about health systems does little to change how that information is used to strengthen the performance of health systems. By engaging national and local decision makers, health policy and systems researchers, scientists from other disciplines, health workers and implementers, development partners, donors and civil society, the Alliance is seeking improved results that are more sustainable, translatable across contexts, and available for all communities. ${ }^{1}$ It will build partnerships with institutions that share its mission: to strengthen health systems in low- and middle-income countries by promoting the generation and use of HPSR.

\section{Acknowledgements}

Some of the ideas and content in this article have been published previously by the authors. ${ }^{1}$

\section{Competing interests}

None declared

\section{Author contributions}

$A G$ and NT drafted the main sections of the paper. EL, ZS and DJ contributed to the drafting of some sections, and to the overall revision and editing of the paper.

\section{References}

1. World Health Organization. Alliance for Health Policy and Systems Research. Strategic plan 2016-2020: investing in knowledge for resilient health systems. Geneva: WHO; 2016 [cited 2016 July 12]. Available from: apps.who.int/ iris/bitstream/10665/204806/1/WHO_HIS_HSR_16.1_eng. pdf

2. Yamey G. What are the barriers to scaling up health interventions in low and middle income countries? A qualitative study of academic leaders in implementation science. Global Health. 2012;8:11.

3. Green A, Bennett S. Sound choices: enhancing capacity for evidence-informed health policy. Geneva: World Health Organization; 2007 [cited 2016 Nov 3]. Available from: www.who.int/alliance-hpsr/resources/Alliance_ BR.pdf

4. Ghaffar A, Tran N, Kieny MP, Etienne C. Putting health policy and systems research on the map. Bull World Health Organ. 2012;90(11):797-797A.

5. Ghaffar A, Tran N, Røttingen JA, Kieny MP. Health policy and systems research: building momentum and community. Bull World Health Organ. 2014;92(12):851.

6. World Health Organization. Alliance for Health Policy and Systems Research. Strategic plan 2011-2015: bridging the worlds of research and policy. Geneva: WHO; 2011 [cited 2016 July 12]. Available from: www.who.int/ alliance-hpsr/alliancehpsr_strategicplan2011.pdf?ua=1

7. Ghaffar A, Tran NT, Reddy KS, Kasonde J, Bajwa T, Ammar W, Mills A. Changing mindsets in health policy and systems research. Lancet. 2013;381(9865):436-7.

8. De Savigny D, Adam T. Systems thinking for health systems strengthening. Geneva: World Health Organization; 2009 [cited 2016 Nov 3]. Available from: apps.who.int/iris/ bitstream/10665/44204/1/9789241563895_eng.pdf

9. Bigdeli M, Peters DH, Wagner AK. Medicines in health systems: advancing access, affordability and appropriate use. Geneva: World Health Organization; 2014 [cited 2016 Nov 3]. Available from: www.who.int/alliance-hpsr/ resources/FR_webfinal_v1.pdf 
10. World Health Organization. Health policy and systems research: a methodology reader. Lucy Gilson (Ed.) Geneva: WHO; 2012 [cited 2016 Nov 3]. Available from: www.who.int/alliance-hpsr/alliancehpsr_reader.pdf

11. Loewenson R, Laurell AC, Hogstedt C, D'Ambruoso L, Shroff Z. Participatory action research in health systems: a methods reader. Harare: EQUINET, TARSC, AHPSR, WHO, IDRC Canada; 2014 [cited 2016 Nov 3]. Available from: www.equinetafrica.org/sites/default/files/uploads/ documents/PAR\%20Methods\%20Reader2014\%20for\%20 web.pdf
12. Peters DH, Tran NT, Adam T. Implementation research in health: a practical guide. Geneva: World Health Organization; 2014 [cited 2016 Nov 3]. Available from: www.who.int/alliance-hpsr/resources/ implementationresearchguide/en/

\section{Copyright: (c) (i) (2)}

(C) 2017 Ghaffar et al. This article is licensed under the Creative Commons Attribution-NonCommercial-ShareAlike 4.0 International Licence, which allows others to redistribute, adapt and share this work non-commercially provided they attribute the work and any adapted version of it is distributed under the same Creative Commons licence terms. See: www.creativecommons.org/licenses/by-nc-sa/4.0/ 